\title{
Comparative Analysis of Induced CD4+ Tregs (Itreg) In Response to CD8+ CTL Induction From PBL By MHC-I Bound Mart-1 Peptide Pulsed DC or Autologous Tumor Cells with Freshly Isolated TIL from Human Melanoma.
}

\author{
Sidharth S Jha ${ }^{1}$, Upendra P Hegde ${ }^{1,2}$ and Nitya G Chakraborty ${ }^{1,2 *}$ \\ ${ }^{1}$ Department of Medicine, University of Connecticut Health Center, Farmington, CT 06030-1628, USA \\ ${ }^{2}$ Carole and Ray Neag Comprehensive Cancer Center, University of Connecticut Health Center, Farmington, CT 06030-1628, USA
}

Received: April 27, 2016; Accepted: May 10, 2016; Published: June 06, 2016

*Corresponding author: Nitya G Chakraborty, University of Connecticut Health Center, Farmington CT, 06030-1628. NGC - Tel: 860-679-1446; Fax: 860-679-1159; E-mail: chakraborty@uchc.edu

\begin{abstract}
CD4 ${ }^{+} \mathrm{CD} 25^{+}$thymus derived Tregs (tTregs) and peripherally induced Tregs (pTreg) are known to control auto-destruction that needs stimulation through major histocompatibility complex-II (MHC-II). For cellular immunotherapy of cancer, tumor associated antigen (TAA, these are also self-antigens) specific in vivo induced CD8+ Cytotoxic T Lymphocytes (CTL) are rapidly eliminated. Under ex vivo condition TAA specific CTL generated with purified $\mathrm{CD} 8^{+}$cells continued to grow and remain active for months. Ex vivo induced CD8+ CTL with un-fractionated Peripheral Blood Lymphocytes (PBL) stimulated with Mart- $1_{27-35}$ A2 peptide pulsed autologous dendritic cells (DC), died within three weeks. Whereas Influenza $\left(\mathrm{Flu}_{58-66}\right)$ peptide antigen specific CTL induced identically, continued to expand and remain functional beyond four weeks. No significant difference between binding affinity of Mart- $1_{27-35}$ peptide and Flu $\mathbf{u}_{58-66}$ peptide to HLA A2 was observed. Upon activation CD8 ${ }^{+}$cells from the cultures expressed MHC-II molecules along with other activation and homing receptors. Expanding $\mathrm{CD} 4^{+}$cells were isolated from In vitro Co-cultures (IVC) with PBL for Mart-1 peptide and Flu peptide. CD4+ cells isolated from Mart-I IVC secreted significantly higher amount of IL-10 and IL-4 upon re-stimulation with autologous DC and/or antiCD3 antibody, than CD4 $4^{+}$cells isolated from Flu PBL IVC. In a similar fashion, $\mathrm{CD} 4^{+}$cells isolated from PBL IVC with autologous Tumor or from freshly obtained tumor tissues were found to secrete significant amount of IL-10, subsequently CD8+ CTLs in such cultures did not survive for long. This finding suggests that $\mathrm{CD} 4^{+} \mathrm{CD} 25^{+} \mathrm{i}$ Treg (or pTreg for in vivo) cells induced in vivo / in vitro, negatively regulate effect or immune response via CD8+ CTL against tumor by elaborating IL-10. In this process activated $\mathrm{CD} 8^{+}$CTL against different antigens might provide differential additional signals via newly expressed MHC-II molecules to the $\mathrm{CD} 4{ }^{+}$cells as needed for different antigens.
\end{abstract}

Keywords: tTreg; pTreg; iTreg; Immune regulation; Tumor immunotherapy

\section{Introduction}

Thymus is not full proof eliminator of self- antigen reactive $\mathrm{T}$ cells hence spontaneously arising TAA specific CTLs could be detected in vivo as well as could be activated for CTL mediated tumor immunotherapy. Unfortunately most of the time such CTLs are short lived. Sakaguchi $[1,2]$ showed that a set of T cells emerging from the thymus naturally as $\mathrm{CD} 4{ }^{+} \mathrm{CD} 25^{+}$regulatory $\mathrm{T}$ cells (nTreg; now termed as tTreg) has a critical role in the control of autoimmune pathology. Tregs cells are also generated in the periphery and are referred to as peripherally inducible Treg (pTreg) cells. Both tTreg and pTregs show regulatory roles in the periphery $[2,3]$. It is not possible to differentiate between tTreg and pTreg when $\mathrm{CD} 4^{+} \mathrm{CD} 25^{+} \mathrm{T}$ cells are isolated from peripheral blood ${ }^{3}$. For the sake of argument it could be said that unless there is a need to stop newly induced self-reactive $\mathrm{T}$ cells (or CTL) in vivo, there is no need for pTreg. These CD4 ${ }^{+}$ pTreg might recognize some ligand (epitope) associated with MHC-II molecules for their activation and expansion. In humans also pTregs are induced from $\mathrm{CD} 4^{+} \mathrm{CD} 25^{-}$cells in response to activation of self reactive cells ${ }^{4}$. Unfortunately the ligand associated with locally available MHC-II molecules are either not known or too difficult to identify such specific ligand in vivo [3]. Previously in ex vivo experiments we have demonstrated iTreg mediated down regulation of CTL response in a relevant human tumor system [5]. We compared freshly isolated Treg cells as natural tTregs with in vitro induced (CD4 $\left.{ }^{+} \mathrm{CD} 25^{+} \mathrm{FoxP} 3^{+}\right)$ iTreg cells. Using Mart- $1_{27-35}$ epitope as a prototypic self-butmelanoma-associated epitope, we tested the effect of these two types of Treg cells on the activation and expansion of the epitope specific CD8 ${ }^{+}$CTL in cultures. We found that tTreg cells were not suppressive towards generating Mart- $1_{27-35}$ epitope specific CTL when the CTL precursors are stimulated by the relevant peptideloaded fully activated DC. On the other hand iTregs emerging from $C D 4^{+} \mathrm{CD} 25^{-}$precursors, in the cultures were found to be significantly suppressive [5]. We further found that while the CTL responses in the Mart-1 model are exquisitely sensitive to suppression by the iTreg, CTL responses against a foreign and dangerous antigen such as influenza Flu 58-66 $_{\text {are not. These results }}$ indicated that when CTL precursors, with specificity for a self but tumor-associated epitope, are optimally stimulated, tTreg are 
not much of an impediment but iTregs are [5]. Growing body of evidence suggests that Treg cells consist of a heterogeneous group of $\mathrm{CD} 4^{+} \mathrm{T}$ cells [6]. Evidence for the negative role of Treg cells on anti-tumor immune response underscores the need for blocking Tregs in tumor immunotherapeutic schema. It is also necessary to find out the possible reason for the induction of pTreg and the epitope (if any) they react to for their expansion to suppress tumor antigen specific CTL. Keeping in mind the difficulties to understand in vivo induction of tumor antigen specific pTreg, in this present work we wanted to induce CD8 ${ }^{+}$ CTL response against tumor associated but self-antigen

Mart- $1_{27-35}$ and Flu derived antigen Flu ${ }_{58-65}$ as foreign antigen using un-fractionated PBL in order to explore the functional characteristics of the $\mathrm{CD} 4{ }^{+} \mathrm{CD} 25^{+}$Treg cells induced in identical culture conditions with the two different antigens. We also worked with $\mathrm{CD}^{+} \mathrm{CD} 25^{+}$cells isolated from PBL + autologous Tumor IVC or from number of freshly obtained tumor tissues. In all these three conditions we found remarkable similarity of IL10 production by induced CD4+CD25+, a common mechanism of stopping self -antigen or tumor reactive CTL expansion.

\section{Materials And Methods}

\section{Study Subjects}

Healthy individuals or melanoma patients were included in the study with appropriate approval from the institute's regulatory board. Blood samples from HLA A2 positive donors were taken for the study with informed consent. The study population consisted of subjects diagnosed with primary cutaneous melanoma with or without systemic metastasis. Informed consent was obtained from each participant who volunteered to donate 50 milliliters peripheral blood, when possible surgically removed tumor tissue. The details of the collection of samples and cell preparation have been described $[5,7]$.

\section{Tissue culture}

Tissue cultures were performed in IMDM medium (HyClone Laboratories Inc., USA) supplemented with 10\% Fetal Bovine Serum (FBS) (GIBCO Inc., USA), henceforth described as complete medium.

\section{T cell purification}

$\mathrm{CD}^{+}$and $\mathrm{CD}^{+} \mathrm{T}$ cells were purified using Dynal magnetic beads (Invitrogen, USA), as described earlier [5]. Purity of the isolated cells was verified and $>98 \%$ pure cells were used for the study.

\section{DC culture}

The method of the generation of myeloid DC from Peripheral Blood Mononuclear Cells (PBMC), used in this study has been described previously $[5,8]$. Briefly, monocytes/macrophages were isolated as adherent cells from Ficoll-Hypaque gradient derived PBMC. The adherent cells were cultured in complete medium containing $1000 \mathrm{U} / \mathrm{ml}$ of GM-CSF (R \& D Systems, Minneapolis, MN) 1000 U/ml of IL-4 (R \& D Systems, Minneapolis, MN) for 7 days. The non-adherent and loosely adherent dendritic cells were harvested by vigorous washing.

\section{Expansion of epitope specific $T$ cells in In vitro co culture (IVC)}

$\mathrm{CD}^{+} \mathrm{T}$ (purity $>98 \%$ ) cells were co cultured with peptide pulsed DC as described earlier [5, 8]. Briefly, human peripheral blood derived CD8+ T cells were co-cultured with autologous DCs pulsed with $100 \mu \mathrm{g} / \mathrm{ml}$ of either Mart- $1_{27-35}$ or Flu $\mathrm{MP}_{58-66}$ peptide (T cells: $\mathrm{DC}=10: 1$ ). These cultures were maintained in complete medium supplemented with $100 \mathrm{U} / \mathrm{ml}$ IL-2. Expansion of antigen specific CTL was quantified 7-10 days post co-culture by staining with respective epitope specific tetramers $\left(1^{\text {st }}\right.$ Stimulation). These CTL were further re-stimulated under similar conditions for 3 more times at 7-10 days interval and the expansion of antigen specific CTL were quantified by tetramer staining before each re-stimulation.

\section{PBL IVC}

$10 \times 10^{6}$ PBMC after Ficoll-Hypaque gradient cut were kept separately in the complete medium without any cytokines or frozen at liquid N2 for later use. Once DC maturation was done, these PBL were co-cultured with autologous DCs pulsed with $100 \mu \mathrm{g} / \mathrm{ml}$ of either Mart- $1_{27-35}$ or $\mathrm{MP}_{58-66}$ peptide (T cells: $\mathrm{DC}=10: 1)$. These cultures were maintained in complete medium supplemented with $100 \mathrm{U} / \mathrm{ml}$ IL-2. Expansion of antigen specific CTL in PBL IVC was quantified 7-10 days post co-culture by staining with respective epitope specific tetramers $\left(1^{\text {st }}\right.$ Stimulation). These PBL IVC were further re-stimulated under similar conditions for 3 more times at 7-10 days interval and the expansion of antigen specific CTL were quantified by tetramer staining before each re-stimulation.

\section{Phenotypic Analysis by flow cytometry}

The immune fluorescence procedure for phenotypic and functional analysis by flow cytometry has been described previously $[5,9]$. For FACS staining, anti-hIFN $\gamma$, anti-hIL-4, antihIL-10, anti-hTNF $\alpha$, anti-hFoxp3, anti-hCD25, anti-hCD62L, anti-h4-1BB, anti-hOX40 and anti-hHLA-DR, DP, DQ antibodies were purchased from BD Biosciences; anti-hIL-2 antibody was procured from Biolegend (San Diego, CA)

\section{Cytokine ELISA}

Cytokines IFN $\gamma$, TNF- $\alpha$, IL-2, IL-4 and IL-10 were quantified by ELISA (Duo Set ELISA Development System, R\&D System, USA) as per manufacturer's protocol.

\section{Tetramer assay}

Analysis for Mart- $1_{27-35}$ antigen specific and $\mathrm{MP}_{58-66}$ antigen specific TCR bearing $\mathrm{T}$ cells has been described previously $[5,8,9]$. The cells from IVC were washed twice in PBS and then incubated with $1 \mu \mathrm{l}$ of $\mathrm{MP}_{58-66}$ or Mart- $1_{27-35}$ conjugated to Allophycocyanin HLA-A2 tetramer (Beckman Coulter Inc., USA), and CD4/CD8 conjugated to FITC or PE (BD Biosciences, USA), at room temperature for 30 minutes. The stained cells were washed twice, and re-suspended in FACS buffer. Thereafter, the number of tetramer positive cells was determined using FACSCalibur (Becton Dickinson, USA) or MACSQuant (Miltenyi Biotech, Bergisch, Gladbach, Germany), and the acquired 
cytofluorographic data were analyzed using the FlowJo software (TreeStar, Ashland, OR).

\section{Tumor Infiltrating Lymphocyte (TIL) isolation and culture}

This has been described earlier [10-12] briefly tumor tissue surgically removed from a melanoma patient was washed in complete medium and cut into very fine pieces with a sterile scissor and then mechanically disrupted by repeated pipetting. A portion of cell suspension obtained from these tissue samples were characterized at day zero for the baseline. While another portion of the cell suspension was cultured in complete medium with or without IL-2 $(100 \mathrm{U} / \mathrm{ml})$ for the TILs to proliferate and melanoma tumor cells to adhere to the base of the culture dish. In the mean time peripheral blood was obtained from the same donor and PBL was isolated as described above. Once the autologous tumor line was ready PBL IVC was setup in presence of autologous tumor and $100 \mathrm{U} / \mathrm{ml}$ of IL-2. These cells were allowed to proliferate for 2-3 weeks before isolating $\mathrm{CD}^{+}$and $\mathrm{CD}^{+}$cells. These cells were cultured separately for 2-3 days in the presence of $100 \mathrm{U} / \mathrm{ml} \mathrm{IL-2}$ before characterization of these cells with or without re-stimulation with anti-CD3 antibody. ELISA was performed with the supernatant as described earlier.

\section{Statistical Analysis}

Statistical analysis was performed according to standard methods for in vitro experiments. Student's T-test was used to derive the statistical significance ( $p$ value 0.05 ) with figure $6 a$.

\section{Results}

Expansion of $\mathrm{CD8}^{+}$CTL for Mart-1 $1_{27-35}$ and FLU $\mathrm{MP}_{58-66}$ epitopes with purified $\mathrm{CD8}^{+}$cells and with unfractionated PBL in co-cultures

We tested the proliferation of Flu $\mathrm{MP}_{58-66}$ and Mart- $1_{27-35}$ epitope specific naturally present $\mathrm{CD}^{+} \mathrm{T}$ cell precursors in cocultures with respective peptide pulsed autologous DC. Figure 1a \& $1 \mathrm{~b}$ show an example of tetramer assay used for determining the expansion of $\mathrm{MP}_{58-66}$ and Mart-1 $1_{27-35}$ epitope specific CD8 ${ }^{+} \mathrm{T}$ cells, respectively. As shown, specific precursors for both the epitopes exhibited substantial expansion following antigen presentation. $\mathrm{MP}_{58-66}$ antigen specific CD8 ${ }^{+}$cells always gave better response than Mart- $1_{27-35}$ antigen specific CD8 ${ }^{+}$. Figure $1 \mathrm{c}$ and $1 \mathrm{~d}$ represent $\mathrm{MP}_{58-66}$ and Mart-1 $1_{27-35}$ antigen specific intracellular IFN- $\gamma$ production by in vitro expanded CD8 ${ }^{+} \mathrm{T}$ cells. $\mathrm{MP}_{58-66}$ and Mart$1_{27-35}$ antigen specific CTL showed specific intracellular IFN- $\gamma$ production and it was further confirmed by ELISA. IFN- $\gamma$ response by antigen specific CD8 ${ }^{+} \mathrm{T}$ cells upon in vitro are stimulation shown in (Figure 1e). There were variations in the precursor frequencies for the two epitopes $\mathrm{MP}_{58-66}$ from 0.05-1.4 and Mart$1_{27-35}$ from 0.01 to 0.50 (data not shown) amongst individual donors, but when compared for fold expansion of the respective epitope specific precursors following stimulation, both $\mathrm{MP}_{58-66}$ and Mart- $1_{27-35}$ epitope specific precursors expanded remarkably well after primary stimulation (Figure 1b). Interestingly, while the fold expansion of Mart- $1_{27-35}$ and Flu $\mathrm{MP}_{58-65}$ epitope specific $\mathrm{T}$ cells following 1st stimulation was comparable, the $\mathrm{MP}_{58-66}$ epitope specific T cells were significantly higher following 2nd stimulation (Figure 1b). After four weeks of initiation of the cultures both Mart- $1_{27-35}$ and Flu $_{58-66}$ specific CTL were very active and secreted significant amount of IFN- $\gamma$ upon stimulation with appropriate antigens (Table 1 and 2).

We then used the same in vitro Co-culture (IVC) method to expand antigen specific $\mathrm{CD}^{+}$cells using total PBL (unfractionated). PBL from donors were stimulated with respective autologous matured DC pulsed with either Mart- $1_{27-35}$ peptide or Flu ( $\left.\mathrm{MP}_{58-66}\right)$ peptide. Cultures were kept in IL-2 (100U/ $\mathrm{ml}$ ) medium. Cultures were re-stimulated with DC pulsed with peptide every 7-10 days. Each time before re-stimulation some cells were taken out for tetramer analysis (Table 3 and 4). Table 3 shows that the expansion of Mart- $1_{27-35}$ antigen specific CD8 ${ }^{+}$ CTL in the co-cultures using PBL from six donors. It is evident from the table that within 21 days Mart- $1_{27-35}$ specific CD8 ${ }^{+} \mathrm{T}$ cells disappeared from the co-cultures. Whereas Table 4 indicates that $\mathrm{Flu}_{58-66}$ specific $\mathrm{CD} 8^{+} \mathrm{CTL}$ continued to expand and remained functional even after 35 days of culture. With all the donors we noticed Mart-1 specific CD8 ${ }^{+} \mathrm{T}$ cells in PBL IVC disappeared post third stimulation. These observations led us to three different thoughts; (a) The above phenomena might be due to significant difference between the binding affinity of Mart- 1 and Flu peptide with A2 molecules on the DCs used for stimulation of the CD8 ${ }^{+}$ cells in PBL IVC, that led to the faster elimination or loss of activity in responding $\mathrm{CD}^{+}$cells; or (b) Since DCs die after antigen presentation in $24 \mathrm{~h}$ the degree of expression of MHC-II molecule by activated $\mathrm{T}$ cells could make the difference. (c) There could be a significant difference between the phenotypic and functional properties of the expanding $\mathrm{CD} 4^{+}$cells, the induced Treg cells, in the co-cultures.

\section{Difference in binding affinity to A2 for Mart-1 and Flu peptide}

We used T2 cells, a gift from Dr. Cresswell (Yale University) [13] to test the binding affinity and stability of the Mart- $1_{27}$ ${ }_{35}$ peptide and Flu $\left(\mathrm{MP}_{58-66}\right)$ peptides on A2 molecule. Figure $2 \mathrm{a}$ describes the binding abilities of those two peptides to A2 molecules. No significant difference in binding affinity between Mart- $1_{27-35}$ peptide and Flu (MP $\left.{ }_{58-66}\right)$ peptides were found. There was a possibility that the two peptides in question have different dissociation time but we found no significant difference in dissociation time between Mart- $1_{27-35}$ peptide and Flu ( $\left(\mathrm{MP}_{58-66}\right)$ peptides.

\section{MHC-II expression by $\mathrm{CD4}^{+}, \mathrm{CD8}^{+}$and DC}

MHC-II expression on $\mathrm{CD}^{+}$and $\mathrm{CD}^{+}$cells were tested before and after stimulation (Figure 2b). Freshly isolated CD $4^{+}$and CD8 ${ }^{+}$ cells were predominantly negative for MHC-II, but a clear spike in MHC-II expression was seen in both activated $\mathrm{CD} 4^{+}$and $\mathrm{CD} 8^{+}$cells (Figure 2b). Both DC and activated CD8 ${ }^{+}$cells in culture expressed MHC-II but there was a significant difference in MFI of MHC-II expressed by DC than activated CD8 ${ }^{+}$cells (Fig. $2 \mathrm{c}$ and $2 \mathrm{~d}$ ).

\section{Characterization of activated $\mathrm{CD4}^{+}$cells induced in the PBL IVCs}

Figure 3 shows a representative data with purified $C D 4^{+}$cells 
Table 1: Functional characterization of expanded $\mathrm{CD}^{+}$Mart-1 antigen specific cells after initial stimulation and re-stimulation with appropriate antigen.

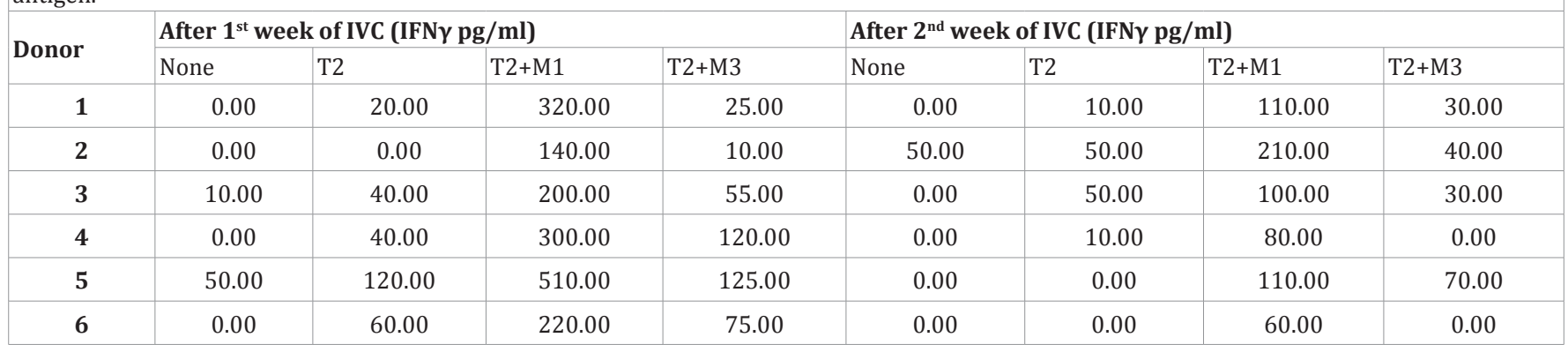

Table 2: Functional characterization of expanded $C D 8^{+}$Flu antigen specific cells after initial stimulation and re-stimulation with appropriate antigen.

\begin{tabular}{|c|c|c|c|c|c|c|c|c|}
\hline \multirow{2}{*}{ Donor } & \multicolumn{4}{|c|}{ After $1^{\text {st }}$ week of IVC (IFN $\left.\gamma \mathrm{pg} / \mathrm{ml}\right)$} & \multicolumn{4}{|c|}{ After $2^{\text {nd }}$ week of IVC (IFN $\left.\gamma \mathrm{pg} / \mathrm{ml}\right)$} \\
\hline & None & $\mathbf{T} 2$ & T2+Flu & $\mathrm{T} 2+\mathrm{M} 3$ & None & T2 & T2+Flu & T2+M3 \\
\hline 1 & 0.00 & 20.00 & 720.00 & 125.00 & 0.00 & 110.00 & 650.00 & 130.00 \\
\hline 3 & 0.00 & 140.00 & 1200.00 & 255.00 & 0.00 & 150.00 & 900.00 & 330.00 \\
\hline 4 & 0.00 & 70.00 & 300.00 & 120.00 & 0.00 & 110.00 & 380.00 & 100.00 \\
\hline 6 & 0.00 & 60.00 & 520.00 & 185.00 & 0.00 & 110.00 & 1060.00 & 330.00 \\
\hline
\end{tabular}

Table 3: Percent of CD8 ${ }^{+}$Mart-1 Tetramer positive cells post $1^{\text {st }}, 2^{\text {nd }}, 3^{\text {rd }}$ and $4^{\text {th }}$ Mart- $1_{27-35}$ antigen specific stimulation in Mart- 1 PBL IVC.

\begin{tabular}{|c|c|c|c|c|}
\hline Donors & 7-10 Days of culture $\left(1^{\text {st }}\right)$ & 14-16 Days of culture $\left(2^{\text {nd }}\right)$ & 21-24 days of culture $\left(3^{\text {rd }}\right)$ & 28-30 days of culture $\left(4^{\text {th }}\right)$ \\
\hline 1 & 1.20 & 3.10 & 0.02 & 0.00 \\
\hline 2 & 2.20 & 0.80 & 0.00 & 0.00 \\
\hline 3 & 0.90 & 1.60 & 0.00 & 0.00 \\
\hline 4 & 0.70 & 4.20 & 0.10 & 0.00 \\
\hline 5 & 1.60 & 2.30 & 0.00 & 0.00 \\
\hline
\end{tabular}

Table 4: Percent of CD8 ${ }^{+}$Flu Tetramer positive cells post $1^{\text {st }}, 2^{\text {nd }}, 3^{\text {rd }}$ and $4^{\text {th }} \mathrm{MP}_{58-66}$ antigen specific stimulation in Flu PBL IVC.

\begin{tabular}{|c|c|c|c|c|}
\hline Donors & 7-10 Days of culture $1^{\text {st }}$ & 14-16 Days of culture $2^{\text {nd }}$ & 21-24 days of culture $3^{\text {rd }}$ & 28-30 days of culture $4^{\text {th }}$ \\
\hline 1 & 2.40 & 3.60 & 3.02 & 3.40 \\
\hline 2 & 1.70 & 2.80 & 2.00 & 2.00 \\
\hline 3 & 0.90 & 2.90 & 1.80 & 2.50 \\
\hline 4 & 0.70 & 6.20 & 5.10 & 5.30 \\
\hline 5 & 1.90 & 4.30 & 2.20 & 3.10 \\
\hline 6 & 2.20 & 2.40 & 3.00 & 5.60 \\
\hline
\end{tabular}

from the cultures. Significantly higher number of $\mathrm{CD}^{+}{ }^{+}$Foxp3 $3^{+}$ cells, were detected in PBL IVCs with Mart-1 peptide (Figure $3 a)$. Before the initiation of the IVCs the percentage of $\mathrm{CD}^{+}$and FoxP3 ${ }^{+}$cells varied from 2.1 to 3.2 in the total PBL (data not shown). When we analyzed for the expression of CD62L, homing receptor and for central memory on these $\mathrm{CD} 4{ }^{+}$cells, we found CD62L is much higher in CD $4^{+}$cells taken from Flu IVCs figure $3 \mathrm{~b}$. While comparing the $\mathrm{CD} 4^{+}$cells isolated from two different IVCs we found 3 times more of CD $4^{+}$cells from Mart- 1 IVC, expressing OX40. We did not detect any significant difference in expression of 4-1BB between these CD4+ cells taken from two different IVCs (Figure $3 b$ ).

$\mathrm{CD}^{+}$cells from the PBL IVCs with Mart- 1 and Flu were purified by positive selection with magnetic beads. These CD4 ${ }^{+}$ cells were then re-stimulated with plate bound anti-CD3 or with autologous DC (responder: stimulator $=10: 1$ ). Figure 4 describes functional profile of $\mathrm{CD}^{+}$cells taken from the PBL cultures by intracellular staining. We found significantly higher levels of IL-10 synthesized by CD4+ ${ }^{+}$cells taken from Mart-1 IVC 


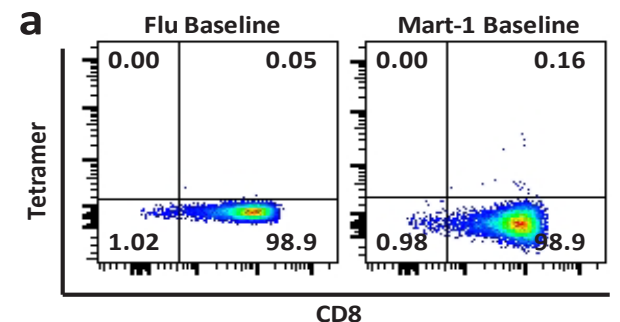

CD8

C

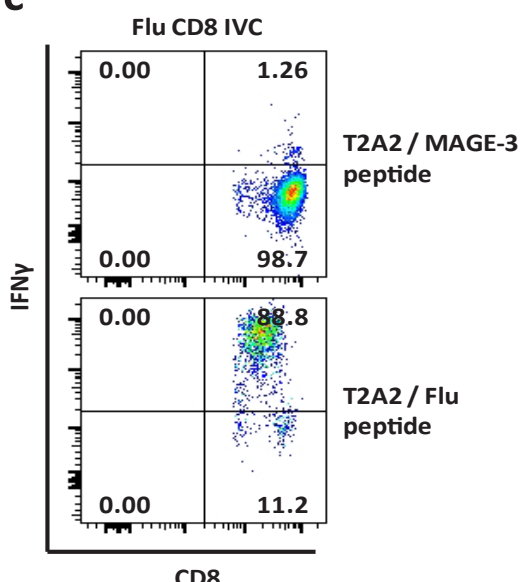

e

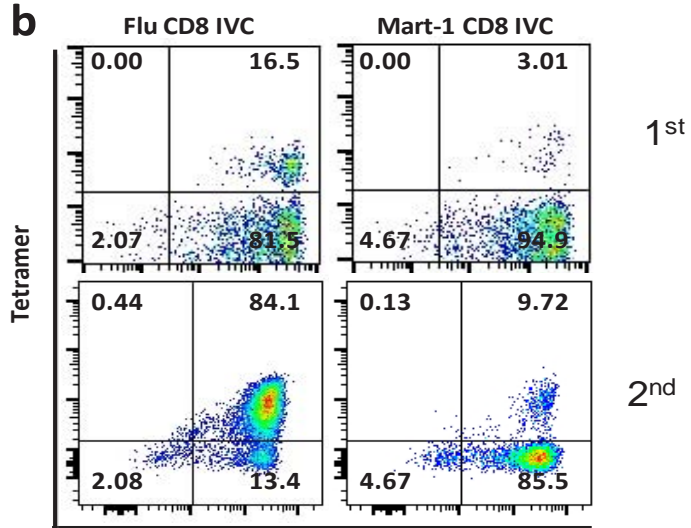

d

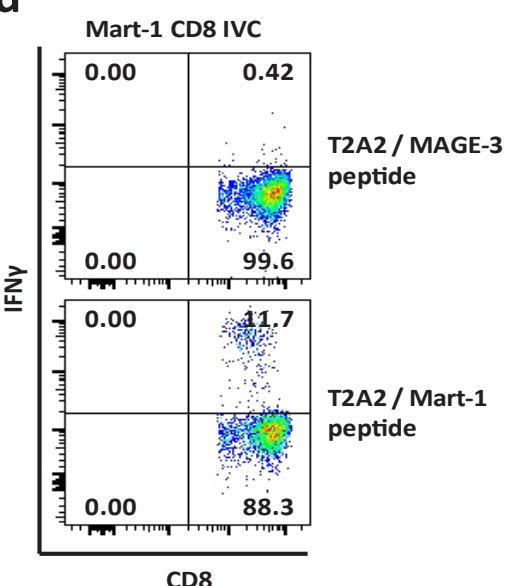

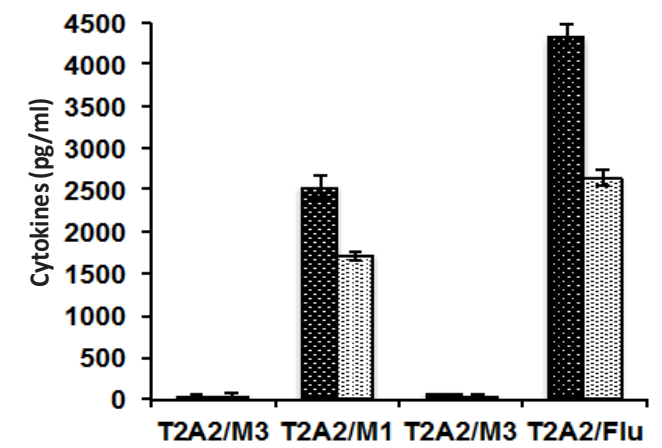

IFNg 1 st stim

घIF Ng 2nd stim

Figure 1: Expansion of Flu MP ${ }_{58-66}$ and Mart- $1_{27-35}$ antigen specific tetramer positive cells in CD8 ${ }^{+}$IVC. Flu MP ${ }_{58-66}$ and Mart- $1_{27-35}$ antigen specific tetramer positive $\mathrm{CD}^{+}$cells at baseline (a) and post first two stimulations with autologous APC in an antigen specific manner (b). Intracellular IFN $\gamma$ expression by expanded Flu $\mathrm{MP}_{58-66}$ (c) and Mart- $1_{27-35}$ (d) tetramer positive CD8 ${ }^{+}$cells on co-culture with T2A2 cells pulsed with either control peptide (MAGE- $3_{271-279}$ ) or cognate peptide (Flu MP ${ }_{58-66}$ or Mart- $1_{27-35}$ ), respectively. Antigen specific IFN $\gamma$ release in the supernatant was estimated $\sim 16$ hours post co-culture by ELISA (e)

than from Flu IVC. IFN- $\gamma$, IL-2 and TNF- $\alpha$, synthesized by these CD4 ${ }^{+}$cells purified from two different IVCs (Mart- 1 and Flu) were comparable (Figure 4).

\section{CD25, FoxP3 and IL-10 expression in CD4 ${ }^{+}$cells derived from TIL and PBL- IVC}

We also looked at the regulatory phenotype of $\mathrm{CD} 4^{+}$cells from freshly obtained tumor tissues (TILs) and PBL tumor IVC in the presence of IL-2. We found $35.5 \%$ TIL derived CD4 ${ }^{+}$cells were CD25 positive (Figure 5a upper panel). Around $12.1 \%$ of these cells were FoxP3 positive while $13.2 \%$ of these cells were IL10 positive (Figure 5a upper panel). In case of PBL + tumor IVC derived $\mathrm{CD}^{+}$cells about $34.7 \%$ were CD25 $5^{+}, 16.8 \%$ were FoxP3 positive and a total of $62.8 \% \mathrm{CD}^{+}$cells were IL-10 positive (Figure 5a lower panel). Further analysis of PBL + autologous tumor IVC derived $\mathrm{CD}^{+} \mathrm{CD} 25^{+}$cells revealed that $42.1 \%$ of these 

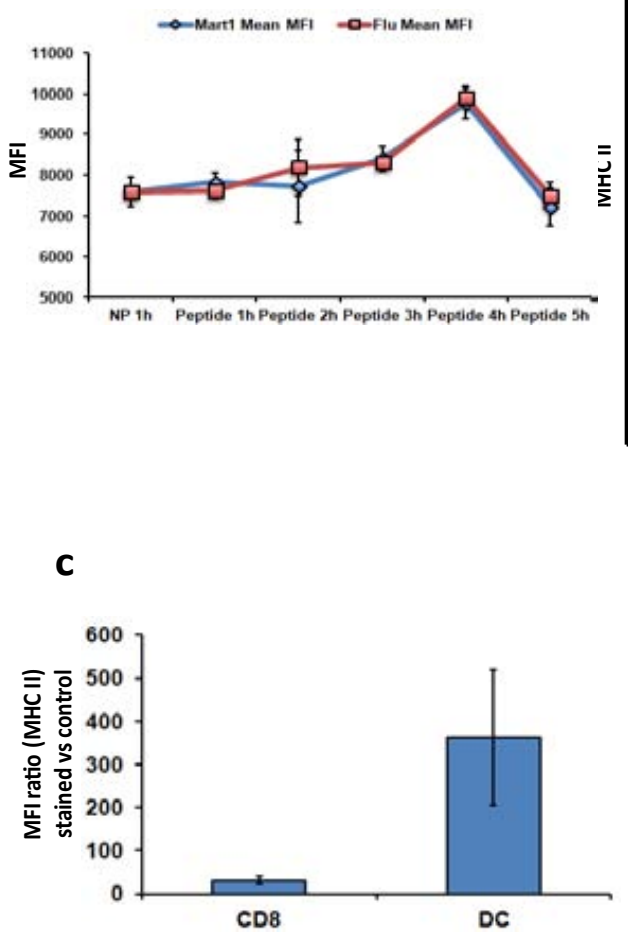

b
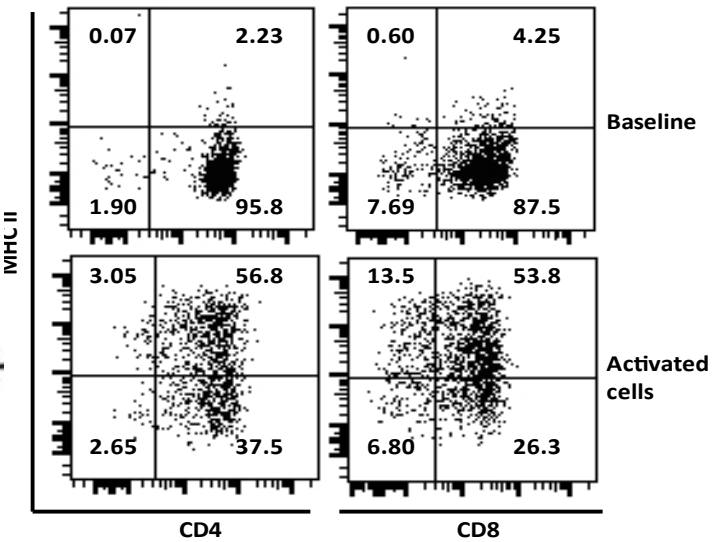

d

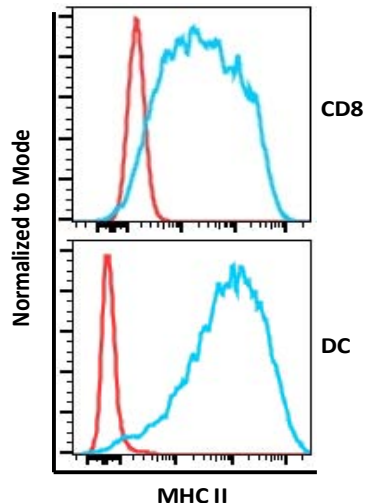

Figure 2: Binding affinity of Mart- $1_{27-35}$ and Flu (MP $\left.{ }_{58-86}\right)$ peptides with HLA A2 and MHC II expression on activated T cells. MFI of Mart- $1_{27.35}$ and Flu ( $\mathrm{MP}_{58-86}$ ) peptide bound HLA A2 molecule on T2 cells were analyzed at 0-4 hour time point (a). MHC II expression was checked by FACS on freshly isolated and activated lymphocytes peripheral (b). The FSC and SSC of activated CD8 and DC's were different. Hence a graph was plotted to show difference between MHC II expression by activated CD8 and DC's. Ratios between MFI of MHC II stained and unstained sample from three individual was used to plot the graph (c). Histogram shows the MFI shift in activated CD8 cells and DC's after staining them with MHC II antibody (d).

cells were Foxp $3^{+}$and $80.0 \%$ of these FoxP3 + cells were IL10 positive (Figure $5 \mathrm{~b}$ ). Around $38 \%$ of $\mathrm{CD} 4{ }^{+} \mathrm{CD} 25^{+}$cells were both IL-10 and Foxp3 positive. From this study it was clear that a significant number of these $\mathrm{CD} 4{ }^{+} \mathrm{CD} 25^{+}$cells stained for IL10 and not all the IL- 10 producing $\mathrm{CD} 4{ }^{+} \mathrm{CD} 25^{+}$cells from PBL tumor IVC were Foxp3 positive (Figure $5 b$ ).

\section{Cytokine ELISA with CD4 ${ }^{+}$cells from PBL tumor IVC on re-stimulation}

PBL tumor IVC derived purified $\mathrm{CD}^{+}$cells did not secret either IL-2 or IL-4 when stimulated with anti CD3 antibody. But these cells did secret low levels of IFN $\gamma$ and TNF (Figure 6a). These $\mathrm{CD}^{+}$cells upon stimulation with anti CD3, secreted very high levels of IL-10. We also found PBL tumor IVC derived purified CD8 ${ }^{+}$cells secreted insignificant amount of IL- 4 and no IL-10 when stimulated with anti CD3 antibody, but were also found to secret IL-2, IFN $\gamma$ and TNF $\alpha$ when re-stimulated with anti CD3 antibody (Figure 6a).We then looked at the cytokine secretion profiles of CD8+ and $\mathrm{CD} 4^{+}$cells taken out from mixed culture and again mixed together in different CD8:CD4 ratios along with anti CD3 antibody. As we increased the number of $\mathrm{CD}^{+}$cells in the cultures of fixed number ofCD8+ cells stimulated with anti-CD3 we did not detect any significant increase in IFN $\gamma$ or $\mathrm{TNF} \alpha$ secretion by $\mathrm{CD} 8^{+}$cells by intracellular cytokine staining indicating no further help to those CD8+ cells. On the contrary at 1:1 ratio (CD8:CD4) the $\mathrm{CD} 4{ }^{+}$cells got additional stimulation and significantly increased the level of IL-10 in the cultures (Figure 6a). A dose dependent response of IL-10 secretion by CD4 ${ }^{+}$ cells was observed when $\mathrm{CD} 4^{+}$cells were mixed in the cultures of $\mathrm{CD}^{+}$cells with anti CD3 antibody stimulation (Figure 6a). In the cultures where equal numbers of $\mathrm{CD} 8^{+}$and $\mathrm{CD} 4^{+}$cells were present, $\mathrm{CD} 4^{+}$cells secreted significantly higher levels of IL-10 (difference mean $\sim 200 \mathrm{pg} / \mathrm{ml}$ ) which is significant $(\mathrm{p}<0.05$ ) than that of those secreted by same number of $\mathrm{CD}^{+}$cells alone upon stimulation with anti CD3 antibody (Figure 6a). These CD4+ cells possibly got additional stimulation provided by $\mathrm{CD}^{+}$cells that helped resulting in increased secretion of IL-10. 
a.

$\begin{array}{cc}\text { CD4 From Flu } & \text { CD4 from Mart-1 } \\ \text { PBL IVC } & \text { PBL IVC }\end{array}$
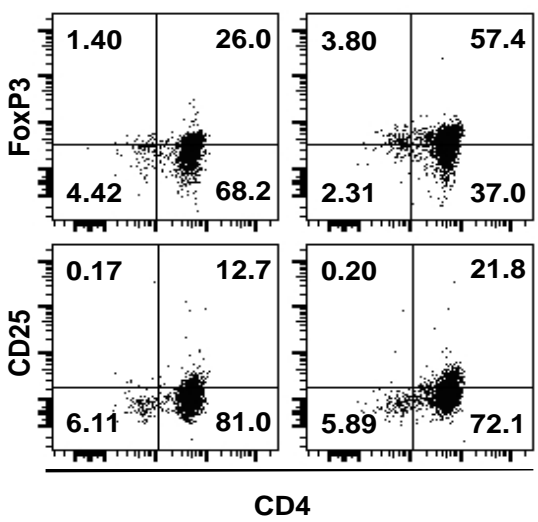

b.

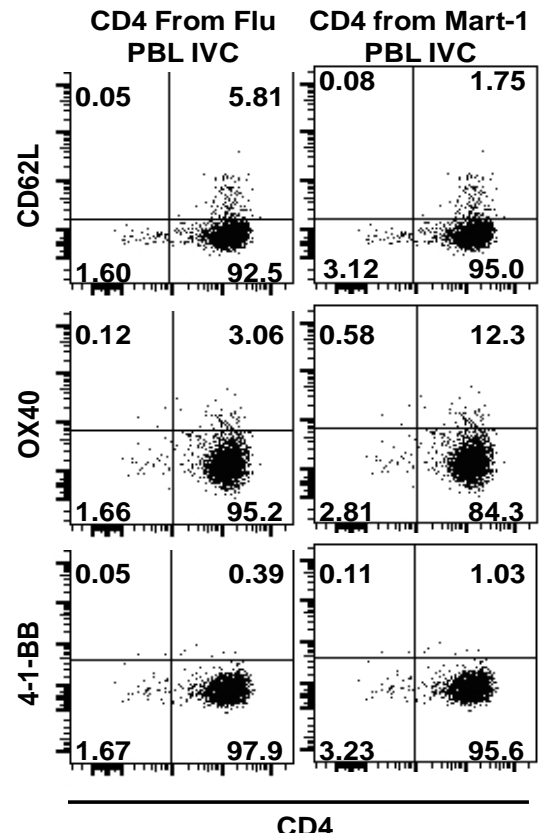

Figure 3: Phenotypic characterization of $\mathrm{CD}^{+}$cells isolated from Flu MP $_{58-66}$ and Mart-1 $\mathbf{1}_{27-35}$ PBL IVC. CD4 ${ }^{+}$cells were isolated from Flu MP ${ }_{58-66}$ and Mart- $1_{27-35}$ antigen specific PBL IVCs after $4^{\text {th }}$ stimulation. Phenotypic analysis of the purified CD $4^{+}$cells from PBL IVC were performed by staining these cells with $\mathrm{CD}_{4}^{+}, \mathrm{CD} 25$ and Foxp3 (a) and CD62L, OX40 and 4-1-BB (b).

\section{Cytokine profile of $\mathrm{CD}^{+}$cells in freshly isolated TILs}

We analyzed lymphocytes from freshly isolated from melanoma tumor tissue before putting them in culture. We observed that significant number of $\mathrm{CD}^{+}$cells were positive for IL-10. So we asked, if CD4 $4^{+}$cells at the tumor site in the presence of very high number of autologous tumor load give a similar response in terms of IL-10 production (Figure 6b). We gated the tumor tissue single cell suspension first for lymphocytes and then sub gated them for $\mathrm{CD} 4^{+}$cells. Analysis of $\mathrm{CD} 4^{+}$cells showed that they were negative for IFN $\gamma$, TNF $\alpha$, IL- 2 and IL-4 cytokines (Figure 6b). But $29.2 \%$ of these $\mathrm{CD}^{+}$cells were positive for intracellular IL-10 (Figure 6b).

\section{Discussion}

$\mathrm{CD}^{+}{ }^{+} \mathrm{CD} 25^{+}$and $\mathrm{Foxp}^{+}$(or FoxP3 negative) regulatory T cells (Tregs) play a critical role in all aspects of immune responses and the control of immune homeostasis [6]. It has become clear that the major population of Foxp $^{+}$Treg is generated in the thymus, previously known as nTreg now it is called tTreg $[3,14]$. It is also clear that certain percentage of Tregs
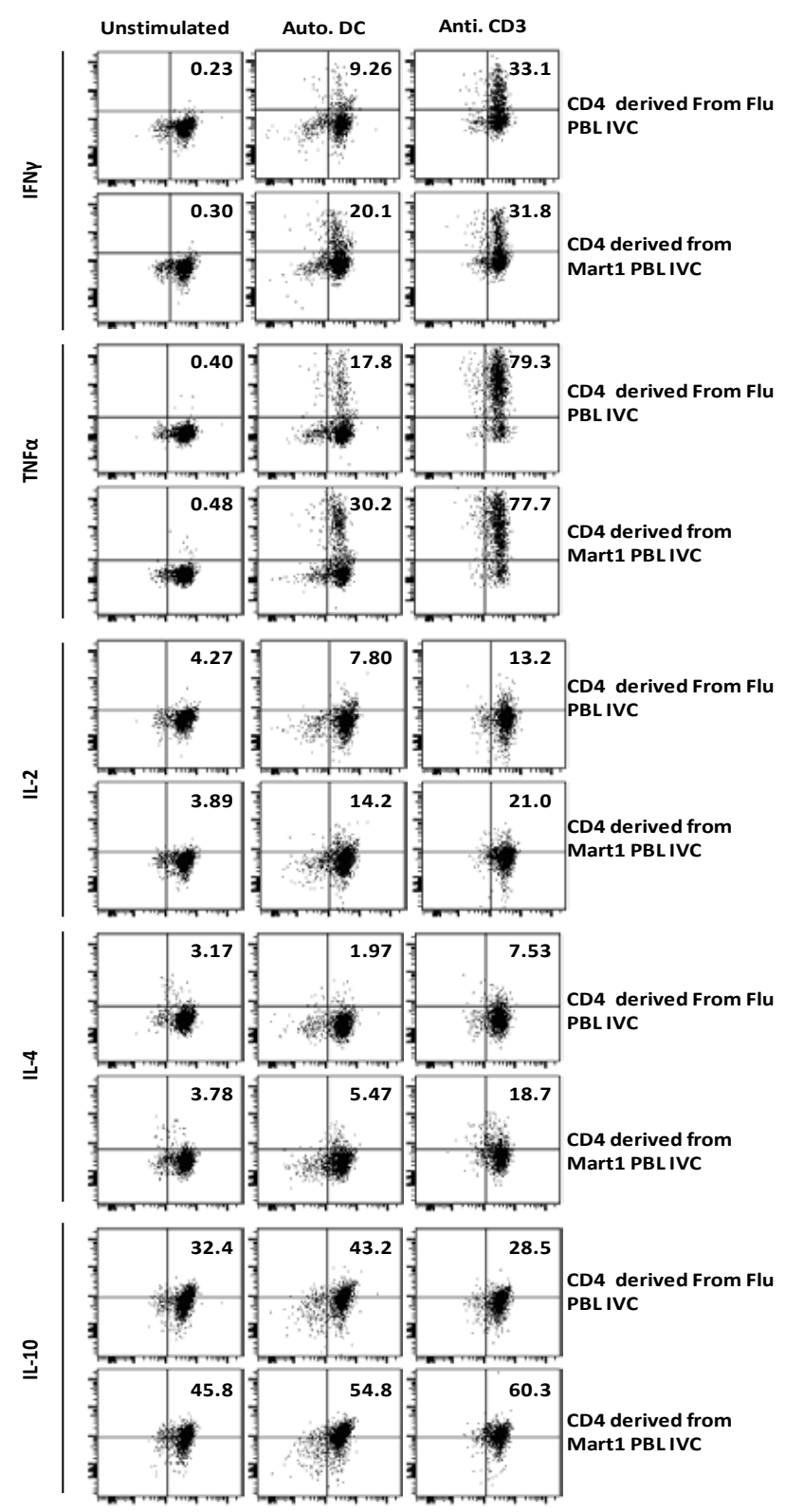

CD4

Figure 4: Functional characterization of $\mathrm{CD}^{+}$cells isolated from Mart- $1_{27-35}$ and Flu MP ${ }_{58-66}$ PBLC: \Users $\backslash$ onlinepc014 \Documents $\backslash$ Downloads $\backslash$ Doc1.docx IVC. CD $4^{+}$were isolated from Mart- $1_{27-35}$ and Flu $\mathrm{MP}_{58-66}$ antigen specific PBL IVC after $4^{\text {th }}$. These CD4 $4^{+}$cells were left un-stimulated, stimulated with autologous APC and stimulated with anti-CD3 antibody, respectively. Intracellular level of cytokines IFN $\gamma$, TNF $\alpha$, IL-2, IL- 4 and IL-10 were tested by FACS. 
a.
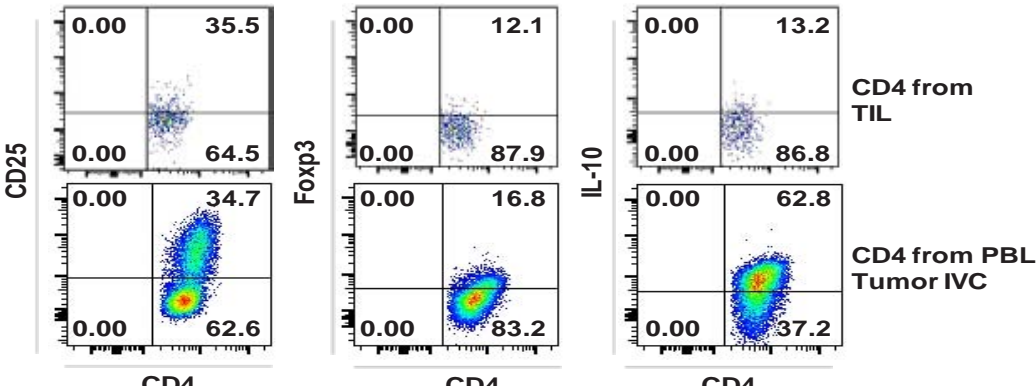

b.
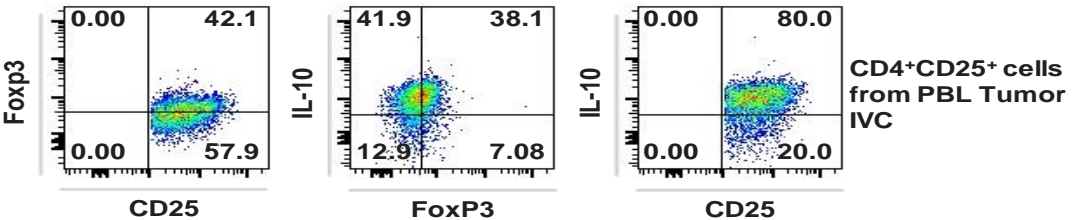

Figure 5: Comparative phenotypic analysis of CD4+ cells isolated from TIL and PBL Tumor IVC. Autologous tumor cell line was generated from surgically removed tumor tissue from a melanoma patient. TILs obtained from the single cell suspension from the tissues were tested. PBL tumor IVC was setup with autologous tumor line in the presence of $100 \mathrm{U} / \mathrm{ml} \mathrm{IL-2}$, and allowed to proliferate for 2-3 weeks before we used them. We looked at the expressions of CD25, Foxp3 and IL-10 on TIL and PBL tumor IVC derived CD4 $4^{+}$cells (a). We further gated CD4 $4^{+}$CD25 $5^{+}$cells from PBL tumor IVC and reanalyzed the data for Foxp3 and IL-10 expression (b).

a.

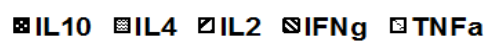

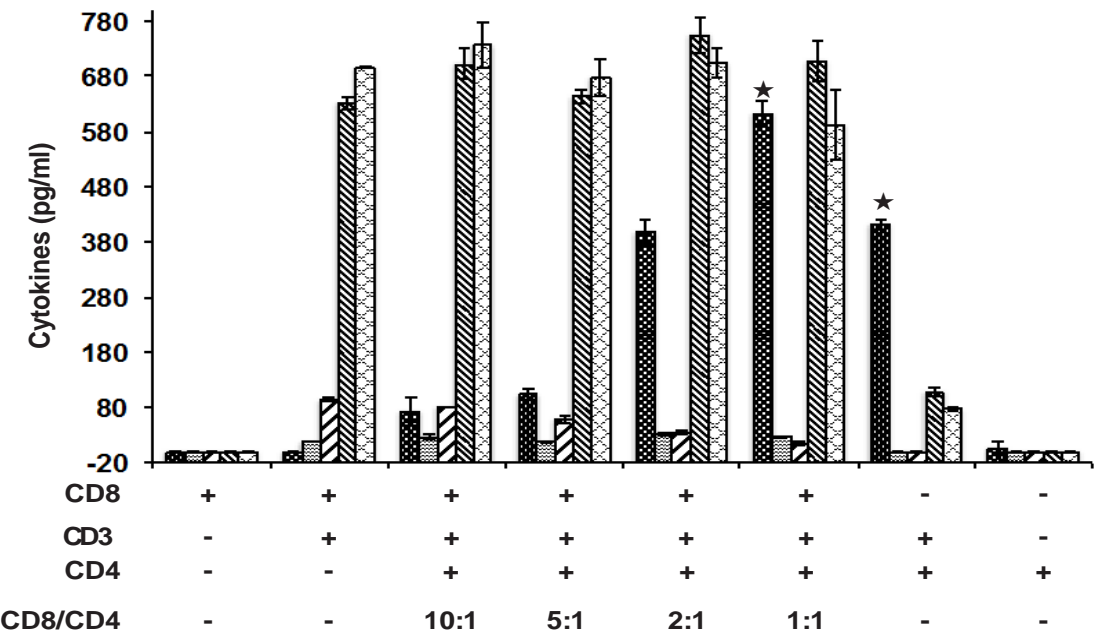

b.
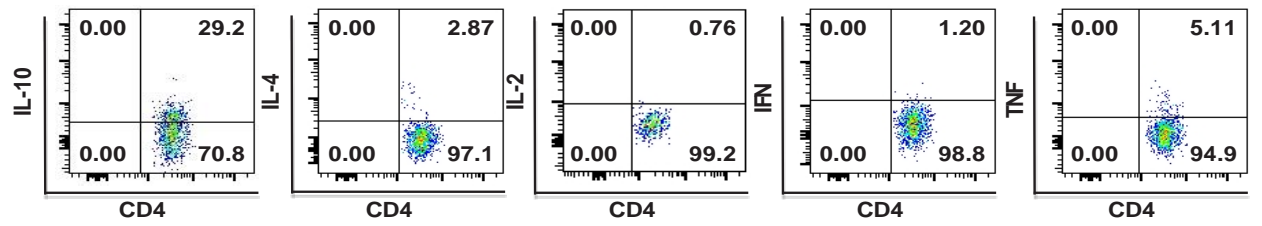

Figure 6: Characterization of CD4 ${ }^{+}$cells isolated from PBL IVC or TILs. IVCs with PBL and autologous tumor were setup in the presence of 100 $\mathrm{U} / \mathrm{ml}$ IL-2. Two weeks after culture, CD8 ${ }^{+} \mathrm{T}$ cells (> $99 \%$ purity) were separated from the culture using Dynal beads while remaining cells were CD $4^{+}$ (>93\% purity). Functional characterization of these $\mathrm{CD}^{+}$cells $\left(2 \times 10^{5}\right.$ cells/well) or CD4+ cells $\left(2 \times 10^{5}\right.$ cells/well) or CD8 ${ }^{+}$and $\mathrm{CD} 4^{+}$cells mixed together (CD8:CD4 ratio of 10:1, 5:1, 2:1 and 1:1) was performed with or without stimulation with anti CD3 antibody (1 $\mu$ g/well). Culture supernatants wee collected and analyzed for cytokines by ELISA (a). Surgically removed melanoma tissue sample was used to generate single cell suspension of Infiltrating Lymphocytes (TIL). Intracellular cytokine (IL-10, IL-4, IL-2, IFN $\gamma$ and TNF $\alpha$ ) staining was done immediately after isolation of TIL from tumor tissue and analyzed by FACS. The samples were first gated for lymphocytes and then sub gated for CD4+ cells (b). 

Freshly Isolated TIL from Human Melanoma

is generated from T-conventional (Tconv) cells in peripheral sites. It has been proposed that such cell populations be termed peripherally derived Tregs (pTregs) [15]. Specificity of tTregs is not established. Although there could be a specific reason for induction of pTregs but how these cells are induced in the periphery, is also not known [14]. It remains unclear whether in vitro induced iTregs and peripherally induced pTregs are similar and that might use the same mechanism for suppression $[3,6]$ of effector immune response. In this article we tried to address the important issues regarding the induction and functions of these pTreg and/or iTreg subpopulations in an in vitro set up. A detailed characterization of these subpopulations has important clinical implications in cellular immunotherapy for cancer $[3,6,14]$. Use of tumor associated antigen specific CD8 ${ }^{+}$ CTL have shown considerable promise in translational tumor immunotherapy [16]. Variety of intrinsic regulatory processes within $\mathrm{T}$ cells as well as a number of microenvironment-based extrinsic mechanisms have turned out to be serious impediments in achieving robust and sustained outcomes of CTL mediated immunotherapy for cancer [16]. A great deal of effort is underway to understand to over come these impediments. Polyclonal tTreg cells do not always influence the immune response by mediating immune suppression or completely shutting down T-cell activation. Thus, polyclonal tTreg cells would not necessarily lead to global immune suppression or the inhibition of effector responses to all antigens [3]. Polyclonal tTregs might specifically target trafficking pathways and not allowing immunity to develop in lymphoid organs. By limiting the number of potentially autoreactive $\mathrm{T}$ cells that are allowed to migrate and enter tissues. That could be the reason for the existence of tumor specific CD8 ${ }^{+}$CTL in tumor tissues. In such conditions a specific Treg cells might be induced from conventional $\mathrm{CD} 4^{+} \mathrm{CD} 25^{-} \mathrm{T}$ cells to work against those auto-reactive $\mathrm{T}$ cells that are generated in the periphery [4, $5,17-20]$.

We have made an attempt to understand the functional properties of the $\mathrm{CD}^{+}$cells isolated from the co-cultures with unfractionated PBL. IL-10 secreted by these cells could dampen the antigen presenting ability of DC as it is already known that iTreg cells suppress DC function and subsequently do suppress $\mathrm{T}$ effector function via IL-10 [5, 12, 21].

Naive and activated $\mathrm{T}$ cells are known to express different adhesion molecules and are thought to exhibit different migratory patterns that result from their expression of discrete adhesion molecules. Two known adhesion molecules that have been associated with differentiating the naive and activated/memory $\mathrm{T}$ cells are CD62L (L-selectin) and CD44 (H-CAM) [22, 23]. In our in vitro $\mathrm{CD}^{+} \mathrm{CTL}$ generation experiments against Mart-1 and Flu we found a marked difference in lymphoid homing receptor expression. It has been demonstrated previously that naive $\mathrm{T}$ cells express a CD62LhiCD44lo phenotype, whereas memory $\mathrm{T}$ cells exhibit a CD62LloCD44hi phenotype [22, 23]. In this regards increased number of CD62L expressing CD4 ${ }^{+}$cells from Flu IVC, could be indicative of memory cells against Flu matrix protein derived antigens, as most of us are exposed to Flu antigen at least once in life time where as Mart-1 being a self antigen no such thing as memory cells were seen.
Analysis of regulatory phenotype of lymphocytes from tumor tissue (TILs) or PBL IVC derived $\mathrm{CD} 4^{+}$cells revealed that, a substantial population of these cells were $\mathrm{CD} 25^{+}$. The number of $\mathrm{CD} 4^{+}$cells expressing CD25 or Foxp3 from those two cultures (TIL or PBL + Tumor IVC) were comparable (Figure 5a). This can be explained by the fact that in both conditions (TIL or PBL+Tumor IVC) $\mathrm{CD}^{+}$cells have already seen the autologous tumor antigen. So in either case the $\mathrm{CD} 4^{+} \mathrm{T}$ cells have seen the tumor antigen and behaved as T regulatory cells to prevent tumor (auto) destruction. The expression of Foxp3 has been shown in both tumor-infiltrating Tregs and melanoma cells by immune histochemical analysis of human melanoma tissue sections [24]. In humans $\mathrm{CD} 4^{+} \mathrm{CD} 25^{-}$effector $\mathrm{T}$ cells can also up regulate Foxp3 expression transiently [4, 20].

Although this work was done with a small group of donors, a difference in pathways for the induction of CD4+pTreg (or iTreg) phenotype (difference in number or function) are clearly seen when antigen specific CTLs (with Mart- $1_{27-35}$ and Flu 58-66 $_{\text {peptides) }}$ were induced. In this study CTL were generated using identically matured autologous DC. When Flu specific CTLs were induced in long term cultures with total PBL, CD8 ${ }^{+} \mathrm{CTL}$ remained active for significantly longer period. CD $4^{+}$cells in cultures and were found to secrete higher amounts of helper cytokine IFN $\gamma$ than IL-10. Since all other conditions remained same, probable indication goes towards the difference in type of antigens. Previously we have shown that $\mathrm{CD}^{+}{ }^{+}$clones, derived from melanoma involved lymph nodes or PBL stimulated by autologous melanoma cells selectively down regulated the induction of cytotoxic immune response against the autologous melanoma cells [7]. We have also shown that repetitive in vitro stimulation with antigen loaded APC could lead to the emergence of non cytolytic CD4 ${ }^{+}$ $\mathrm{T}$ cells secreting suppressor factor in culture supernatant. This inhibitory effect of supernatant factor could be abrogated by neutralizing IL-10 with anti IL-10 antibody [12].

Expression of MHC II molecules by activated T cells from humans is regulated by CIITA-PIII subtype of the class II trans activator (CIITA) [25]. Direct ex vivo expression of MHC-II in the context of CD [25] high identifies a mature, functionally distinct regulatory $\mathrm{T}$ cell population involved in contact dependent in vitro suppression [26]. So circulating human peripheral blood derived T cells can express MHC class II $[27,28]$, but mice T cells cannot transcribe CIITA required for MHC II expression $[29,30]$. It has been shown earlier that MHC II DR on human T cells, primarily being regarded as a marker for activation [30 32]. The expression of class II on $\mathrm{CD}^{+} \mathrm{T}$ cells is inducible and Class $\mathrm{II}^{+} \mathrm{CD} 4^{+} \mathrm{T}$ cells can present antigen in the absence of APC [33]. It has been reported that suppression of TCR transgenic $\mathrm{CD}^{+} \mathrm{T}$ cells stimulated with soluble peptide was mediated via a $\mathrm{T}$ - $\mathrm{T}$ interaction with activated $\mathrm{CD} 4{ }^{+} \mathrm{CD} 25^{+} \mathrm{T}$ cells [34]. Antibody blocking of MHC II on human activated regulatory T cells abrogated their suppressive potential [35]. In our study we also found that naïve $\mathrm{CD}^{+}$cells do not express MHC-II molecules. After stimulation with DC pulsed with HLA A2 binding peptides or tumor cells expression of MHC-II molecule (newly synthesized) was seen. MHC-II expressed by activated CD8 ${ }^{+}$cells were not simply shaded off MHC-II molecules from the DCs in 
the cultures (Figure 2b). Purified CD8 ${ }^{+}$CTL from the cultures maintained their expression of MHC-II molecules as long as they survived (4-8 weeks) in cultures. Newly expressed MHC II on $\mathrm{CD}^{+}$activated cells and the additional stimulatory effect of such cells on expanding $\mathrm{CD}^{+}$cells (Figure $6 \mathrm{a}$ ) indicated that activated CD8 ${ }^{+}$CTL could also provide important signal for the outcome of the immune reaction (rejection or tolerance).The IL-10 secreted by $\mathrm{CD}^{+}$cells was able to suppress $\mathrm{CD} 8^{+}$CTL expansion in IVC with PBL plus autologous tumor. It has been reported earlier that iTregs could regulate CTL response through IL-10 in vitro and also in vivo $[3,5,12,21,26]$. Further detailed work is needed to understand the mechanism behind this differential activation of induced Treg (or pTregs) cells and the role of $\mathrm{MHC}-\mathrm{II}^{+} \mathrm{CD}^{+} \mathrm{CTLs}$ to that.

Tumor associated peptide antigen pulsed DC or whole tumor cells when presented to autologous lymphocytes in the in vitro cultures, induced a class of CD4+CD25+ cells that secreted significant amount of IL-10 and controlled the expansion of CD8 ${ }^{+}$ CTLs. A similar picture was seen in vivo, where we analyzed freshly isolated lymphocytes from the surgically removed tumor tissues. Whether peptide antigens or tumor cells when used to stimulate autologous lymphocytes in cultures a clonal (oligo or polyclonal) population of $\mathrm{CD}^{+}$were induced that secreted significant amount of IL-10 and controlled CTL expansion. An identical in vivo picture was seen when we analyzed freshly isolated lymphocytes from surgically removed tumor tissues. Hence the overall negative regulation is maintained by induced CD4 ${ }^{+} \mathrm{CD} 5+$ cells (possibly) pTregs via IL-10, and $\mathrm{MHC}-\mathrm{II}^{+} \mathrm{CD}^{+}$ activated $\mathrm{T}$ cells could also provide signals through newly synthesized MHC molecules in the in vivo micro environment and in vitro cultures.

\section{Acknowledgements}

This work was supported by a grant from Richard and Jane Lublin (UPH), and MO 1RR06192 from GCRC, UCHC.

\section{References}

1. Sakaguchi S. Naturally arising CD4+ regulatory t cells for immunologic self-tolerance and negative control of immune responses. Annu Rev Immunol. 2004;22:531-562.

2. Sakaguchi S. Naturally arising Foxp3-expressing CD25+CD4+ regulatory $\mathrm{T}$ cells in immunological tolerance to self and non-self. Nat Immunol. 2005;6(4):345-352.

3. Shevach EM, Thornton AM. tTregs, pTregs, and iTregs: similarities and differences. Immunol Rev 2014;259(1):88-102. doi: 10.1111/ imr. 12160

4. Walker MR, Kasprowicz DJ, Gersuk VH, Benard A, Van Landeghen M, Buckner JH, et al. Induction of FoxP3 and acquisition of T regulatory activity by stimulated human CD4+CD25- T cells. J Clin Invest. 2003;112(9):1437-1443. doi: 10.1172/JCI200319441

5. Chattopadhyay S, Mehrotra S, Chhabra A, Hegde U, Mukherji B, Chakraborty NG. Effect of CD4+CD25+ and CD4+CD25- T regulatory cells on the generation of cytolytic $\mathrm{T}$ cell response to a self but human tumor-associated epitope in vitro. J Immunol. 2006;176(2):984-990.

6. Akbar AN, Vukmanovic-Stejic M, Taams LS, Macallan DC. The dynamic co-evolution of memory and regulatory CD4+ T cells in the periphery.
Nat Rev Immunol. 2007;7(3):231-237.

7. Chakraborty NG, Twardzik DR, Sivanandham M, Ergin MT, Hellstrom KE, Mukherji B. Autologous melanoma-induced activation of regulatory $\mathrm{T}$ cells that suppress cytotoxic response. J Immunol. 1990;145(7):2359-2364.

8. Mehrotra S, Chhabra A, Chakraborty A, Chattopadhyay S, Slowik M, Stevens R, et al. Antigen presentation by MART-1 adenovirustransduced interleukin-10-polarized human monocyte-derived dendritic cells. Immunology. 2004;113(4):472-481.

9. Jha SS, NG Chakraborty, P Singh, B Mukherji, and DI Dorsky. Knockdown of T-bet expression in Mart-127-35-specific T-cellreceptor-engineered human CD4+ CD25- and CD8+ T cells attenuates effector function. Immunology. 2014;145(1):124-35. doi: 10.1111/ imm.12431

10. Chakraborty NG, Sporn JR, Tortora AF, Kurtzman SH, Yamase H, Ergin MT, et al. Immunization with a tumor-cell-lysate-loaded autologousantigen-presenting-cell-based vaccine in melanoma. Cancer Immunol Immunother. 1998;47(1):58-64.

11. Mukherji B, Chakraborty NG, Yamasaki S, Okino T, Yamase H, Sporn JR, Kurtzman SK, Ergin MT, Ozols J, Meehan J, et al. Induction of antigenspecific cytolytic T cells in situ in human melanoma by immunization with synthetic peptide-pulsed autologous antigen presenting cells. Proc Natl Acad Sci U S A. 1995;92(17):8078-8082.

12. Chakraborty NG, Li L, Sporn JR, Kurtzman SH, Ergin MT, Mukherji B. Emergence of regulatory $\mathrm{CD} 4+\mathrm{T}$ cell response to repetitive stimulation with antigen-presenting cells in vitro: implications in designing antigen-presenting cell-based tumor vaccines. J Immunol. 1999;162(9):5576-5583.

13. Androlewicz MJ, Anderson KS, Cresswell P. Evidence that transporters associated with antigen processing translocate a major histocompatibility complex class I-binding peptide into the endoplasmic reticulum in an ATP-dependent manner. Proc Natl Acad Sci U S A. 1993;90(19):9130-9134.

14. Karimi S, Chattopadhyay S, Chakraborty NG. Manipulation of regulatory $\mathrm{T}$ cells and antigen-specific cytotoxic $\mathrm{T}$ lymphocyte-based tumour immunotherapy. Immunology. 2014;144(2):186-196. doi: 10.1111/imm.12387.

15. Abbas AK, Benoist C, Bluestone JA, Campbell DJ, Ghosh S, Hori S, et al. Regulatory T cells: recommendations to simplify the nomenclature. Nat Immunol. 2013;14(4):307-308. doi: 10.1038/ni.2554.

16. Ray S, Chhabra A, Mehrotra S, Chakraborty NG, Ribas A, Economou J, et al. Obstacles to and opportunities for more effective peptidebased therapeutic immunization in human melanoma. Clin Dermatol. 2009;27(6):603-613. doi: 10.1016/j.clindermatol.2008.09.019.

17. Zheng SG, Wang JH, Gray JD, Soucier H, Horwitz DA. Natural and induced CD4+CD25+ cells educate CD4+CD25- cells to develop suppressive activity: the role of IL-2, TGF-beta, and IL-10. J Immunol. 2004;172(9):5213-5221.

18. Chen W, Jin W, Hardegen N, Lei KJ, Li L, Marinos N, et al. Conversion of peripheral CD4+CD25- naive $\mathrm{T}$ cells to $\mathrm{CD} 4+\mathrm{CD} 25+$ regulatory $\mathrm{T}$ cells by TGF-beta induction of transcription factor Foxp3. J Exp Med. 2003;198(12):1875-1886.

19. Park HB, Paik DJ, Jang E, Hong S, Youn J. Acquisition of anergic and suppressive activities in transforming growth factor-betacostimulated CD4+CD25- T cells. Int Immunol. 2004;16(8):12031213.

20. Walker MR, Carson BD, Nepom GT, Ziegler SF, Buckner JH. De novo 
generation of antigen-specific CD4+CD25+ regulatory $\mathrm{T}$ cells from human CD4+CD25- cells. Proc Natl Acad Sci U S A. 2005;102(11):41034108.

21. Chattopadhyay G, Shevach EM. Antigen-specific induced T regulatory cells impair dendritic cell function via an IL-10/MARCH1-dependent mechanism. J Immunol. 2013;191(12):5875-5884. doi: 10.4049/ jimmunol.1301693.

22. Gerberick GF, Cruse LW, Miller CM, Sikorski EE, Ridder GM. Selective modulation of $\mathrm{T}$ cell memory markers CD62L and CD44 on murine draining lymph node cells following allergen and irritant treatment. Toxicol Appl Pharmacol. 1997;146(1):1-10.

23. Hengel RL, Thaker V, Pavlick MV, Metcalf JA, Dennis G Jr, Yang J, et al. Cutting edge: L-selectin (CD62L) expression distinguishes small resting memory $\mathrm{CD} 4+\mathrm{T}$ cells that preferentially respond to recall antigen. J Immunol. 2003;170:28-32.

24. Niu J, Jiang C, Li C, Liu L, Li K, Jian Z, et al. Foxp3 expression in melanoma cells as a possible mechanism of resistance to immune destruction. Cancer Immunol Immunother. 2011;60:1109-1118. doi: 10.1007/s00262-011-1025-3

25. Holling TM, Schooten E, Langerak AW, van den Elsen PJ. Regulation of MHC class II expression in human T-cell malignancies. Blood. 2004;103(4):1438-1444.

26. Baecher-Allan C, Wolf E, Hafler DA. MHC class II expression identifies functionally distinct human regulatory T cells. J Immunol. 2006;176(8):4622-4631.

27. Ko HS, Fu SM, Winchester RJ, Yu DT, Kunkel HG. Ia determinants on stimulated human T lymphocytes. Occurrence on mitogen- and antigen-activated T cells. J Exp Med. 1979;150(2):246-255.

28. Evans RL, Faldetta TJ, Humphreys RE, Pratt DM, Yunis EJ, Schlossman
SF. Peripheral human T cells sensitized in mixed leukocyte culture synthesize and express Ia-like antigens. J Exp Med. 1978;148(5):1440 1445.

29. Holling TM, van der Stoep N, Quinten E, van den Elsen PJ. Activated human T cells accomplish MHC class II expression through $\mathrm{T}$ cellspecific occupation of class II transactivator promoter III. J Immunol 2002;168(2):763-770.

30. Lamb JR, Fledmann M. A human suppressor T cell clone which recognizes an autologous helper T cell clone. Nature. 1982;300:456458. doi:10.1038/300456a0

31. LaSalle JM, Ota K, Hafler DA. Presentation of autoantigen by human T cells. J Immunol. 1991;147(3):774-780.

32. LaSalle JM, Tolentino PJ, Freeman GJ, Nadler LM, Hafler DA. Early signaling defects in human T cells anergized by $\mathrm{T}$ cell presentation of autoantigen. J Exp Med. 1992;176(1):177-186.

33. Mangalam A, Rodriguez M, David C. Role of MHC class II expressing CD4+ T cells in proteolipid protein(91-110)-induced EAE in HLADR3 transgenic mice. Eur J Immunol. 2006;36(12):3356-3370.

34. Piccirillo CA, Shevach EM. Cutting edge: control of CD8+ T cell activation by $\mathrm{CD} 4+\mathrm{CD} 25+$ immunoregulatory cells. J Immunol. 2001;167(3):1137-1140.

35. Peiser M, Becht A, Wanner R. Antibody blocking of MHC II on human activated regulatory $\mathrm{T}$ cells abrogates their suppressive potential. Allergy. 2007;62(7):773-780.

36. Chakraborty NG, Chattopadhyay S, Mehrotra S, Chhabra A, Mukherji B. Regulatory T-cell response and tumor vaccine-induced cytotoxic $\mathrm{T}$ lymphocytes in human melanoma. Hum Immunol. 2004;65(8):794802. 